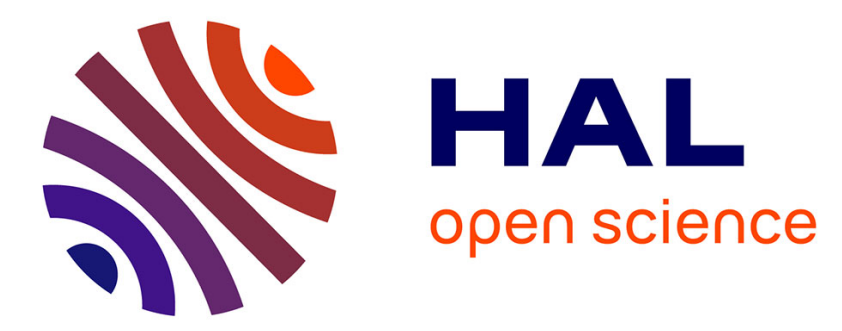

\title{
Structural Control of Bisurea-Based Supramolecular Polymers: Influence of an Ester Moiety
}

Mohammed Dirany, Virgile Ayzac, Benjamin Isare, Matthieu Raynal, Laurent Bouteiller

\section{- To cite this version: \\ Mohammed Dirany, Virgile Ayzac, Benjamin Isare, Matthieu Raynal, Laurent Bouteiller. Structural Control of Bisurea-Based Supramolecular Polymers: Influence of an Ester Moiety. Langmuir, 2015, 31 (42), pp.11443-11451. 10.1021/acs.langmuir.5b02974 . hal-01696685}

\section{HAL Id: hal-01696685 \\ https://hal.science/hal-01696685}

Submitted on 25 Aug 2020

HAL is a multi-disciplinary open access archive for the deposit and dissemination of scientific research documents, whether they are published or not. The documents may come from teaching and research institutions in France or abroad, or from public or private research centers.
L'archive ouverte pluridisciplinaire HAL, est destinée au dépôt et à la diffusion de documents scientifiques de niveau recherche, publiés ou non, émanant des établissements d'enseignement et de recherche français ou étrangers, des laboratoires publics ou privés. 


\title{
Structural control of bisurea-based supramolecular
}

\section{polymers: influence of an ester moiety.}

\author{
Mohammed Dirany,,$^{\dagger}$ Virgile Ayzac, ${ }^{\dagger}$ Benjamin Isare ${ }^{\dagger}$ Matthieu Raynal ${ }^{* \dagger}$ and Laurent
}

Bouteiller*t

'Sorbonne Universités, UPMC Univ Paris 06, CNRS, Institut Parisien de Chimie Moléculaire, Equipe Chimie des Polymères, 4 Place Jussieu, F75005 Paris, France.laurent.bouteiller@upmc.fr ; matthieu.raynal@upmc.fr

Abstract A few examples of monomers are known which self-assemble into various high molar mass structures in solution. Controlling the morphology of the resulting supramolecular polymers is a highly desirable goal for many applications. Herein, we compare the selfassembling properties of newly prepared ester bisurea monomers with those of previously investigated alkyl bisurea monomers. The ester functionality decreases the hydrogen bonding strength of the bisurea monomers but does not prevent the formation of long assemblies in nonpolar solvents: gels are formed at millimolar concentration. Surprisingly, ester bisureas selfassemble at room temperature into rod-like urea-bonded supramolecular polymers that are different from the ones formed by alkyl bisureas. The rods formed by ester bisurea supramolecular polymers are compact (instead of tubular in the case of alkyl bisureas) and display two monomers in the cross-section (instead of three in the case of alkyl bisureas). The stability of the structures formed by ester bisureas can be easily tuned by changing the nature of the substituent in the $\alpha$-position of the urea functions and/or the nature of the alkyl side chains.

\section{Introduction}


The chain-like assembly of self-complementary monomers by means of reversible, dynamic and directional non-covalent interactions provides supramolecular polymers: a class of compounds with unique properties and applications..$^{1-4}$ Notably, the responsiveness ${ }^{5}$ of supramolecular polymers towards a range of stimuli has contributed to the development of innovative optoelectronic materials ${ }^{6-8}$ self-healing materials, ${ }^{9-11}$ chiroptical switches ${ }^{12,13}$ and gels ${ }^{14,15}$ amongst other applications. Ongoing efforts in the field are devoted to a better control of their mechanism of formation ${ }^{16-18}$ (and its associated energetic/kinetic pathways) ${ }^{19-23}$ as it governs the final polymeric structure in terms of its length and composition. ${ }^{24-29}$ Altogether with a deeper understanding of the organization of the assemblies at the molecular level, it will lead to the emergence of sophisticated functional materials. ${ }^{30}$

Synthetic supramolecular polymers are composed of homo- or heteropolytopic monomers which assemble into polymer-like aggregates that can further form macrocycles, fibers, micelles or in rare cases more complex structures including tapes, ribbons, tubes, cylindrical micelles or vesicles. The final morphology of the polymers is hardly predictable as it depends on the conformation of the monomers at the molecular level (e.g. the shape of the repeating unit), the relative arrangement of the monomers in the self-assemblies and the ability of discrete selfassemblies to associate into hierarchical structures (e.g. $\alpha$-helices which assemble into coiledcoil). Nevertheless, controlling the morphology of the polymers in solution is a highly desirable

task. A possible strategy consists in designing self-complementary monomers possessing welldefined primary associating units able to enforce a polymeric morphology, and to probe the effect of additional, weakly interacting, moieties. These secondary features may allow to slightly alter the morphology of the polymeric structures, and in some cases to lead to hierarchical nanostructures. ${ }^{31-40}$ Controlling the assemblies of such monomers is of particular interest as they 
can be used to design discrete, dynamic and reversible functional polymers for applications as conductive materials ${ }^{41}$ and catalysts. ${ }^{42-47}$
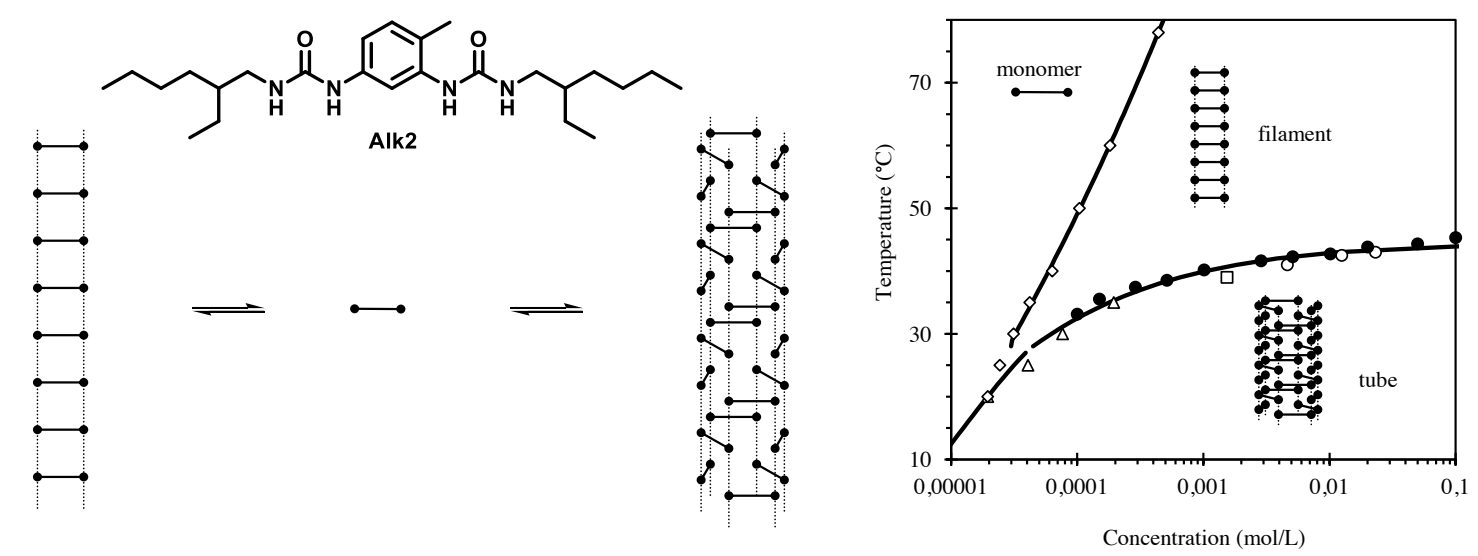

Figure 1. Left: schematic representation of the self-assembly behavior of Alk 2 (hydrogen bonds are symbolized by dotted lines connecting the urea functions.) Right: pseudo-phase diagram of Alk2, with structural transitions determined by various analytical techniques. ${ }^{48}$

We have applied this strategy to structurally-simple alkyl bisureas (Alk1-3, Scheme 1) that were shown to form two types of long supramolecular polymers exhibiting distinct properties in solution (Figure 1). ${ }^{48-50}$ At low temperature and high concentration, long and rigid self-assemblies are formed which are able to gelate apolar solvents. This structure is actually tubular and contains three bisurea molecules in the cross-section. Upon increasing the temperature or upon dilution, the tubular structure cooperatively transforms into filaments (i.e. long one-dimensional fibers with a single monomer in the cross-section). For Alk2, the morphology and geometrical features of both the tubular and filament structures have been characterized in solution ${ }^{48-50}$ by means of various analytical techniques, and models of the molecular arrangement of the monomers within the assemblies have been proposed based on molecular mechanics/molecular dynamics (MM/MD) simulations..$^{51-53}$ The transition between the two structures can be followed 
by spectroscopic or calorimetric techniques yielding a pseudo-phase diagram which highlights the predominance domains of each structure in solution (Figure 1). ${ }^{48}$

Previous work in our group has shown that the relative thermodynamic stability of the tube and filament structures can be tuned by simple modification of the bisurea monomers, notably by changing the nature of the aromatic spacer ${ }^{54-56}$ However, in all these cases, no significant difference in the morphologies of the resulting polymers has been observed. In our ongoing studies, we are interested to probe whether introducing an ester function at the $\beta$-position of the urea assembling units would affect the self-assembly properties of bisurea monomers. We show herein that bisureas derived from amino-ester (ester bisureas) assemble into filaments in competition with rod-like polymers in solution but that the latter are different from the classical tubular structure of alkyl bisureas. The influence of the ester function is also precisely investigated by comparing the stabilities of the hydrogen-bonded species. Our results highlight the structural versatility of bisurea-based supramolecular polymers in solution.

\section{Experimental Section}

Synthesis of the bisurea monomers. The detailed synthesis and characterization of Est1-Est4 and their precursors are reported in the Supporting Information.

Sample preparation for spectroscopic analyses. The desired bisurea was weighed into a glass vial, the volume was adjusted to the desired end concentration with an adequate glass microsyringe, and checked by weighing the sample. Vials were stoppered and briefly heated to ensure full dissolution of the bisurea compounds.

Small-angle neutron scattering. Small-angle neutron scattering measurements were made at the LLB (Saclay, France) on the Pace instrument, at two distance-wavelength combinations to cover the $410^{-3}$ to $0.24 \AA^{-1} \mathrm{q}-$ range, where the scattering vector $\mathrm{q}$ is defined as usual, assuming elastic 
scattering $(\mathrm{q}=(4 \pi / \lambda) \sin (\theta / 2)$, where $\theta$ is the angle between incident and scattered beam). Data were corrected for the empty cell signal and the solute and solvent incoherent background. A light water standard was used to normalize the scattered intensities to $\mathrm{cm}^{-1}$ units.

The following form factor for infinitely long rigid fibrillar objects of homogeneous contrast (specific contrast, $\overline{\Delta b}^{2}$ ) and circular cross-section (radius, $r$ ) was used to fit the data for Alk1-3 and for Est1-4 at $20^{\circ} \mathrm{C:}^{50,57}$

$$
I=\frac{\pi c}{q} \overline{\Delta b}^{2} \frac{n_{L} M_{0}}{N_{a}}\left[2 \frac{J_{1}(q r)}{q r}\right]^{2}
$$

$N_{a}$ is Avogadro number, $c$ the concentration $\left(\mathrm{g} . \mathrm{cm}^{-3}\right), M_{0}$ the bisurea molar mass and $J_{l}$ the Bessel function of the first kind. The values of the specific contrast $\left(\overline{\Delta b}^{2}\right)$ were calculated based on the measured density of Alk2 (1.06 g.cm $\left.{ }^{-3}\right)$ and are given in Table S1.

The experimental curves were adjusted by linear regression in a $\ln (q I)$ versus $q^{2}$ plot. The number $n$ of molecule in the cross-section can be derived from $n_{L}$ (the number of molecule per unit length) by assuming an average intermolecular distance of $4.6 \AA$, which is the usual spacing for hydrogen bonded urea groups:

$$
n=4.6 \times n_{L}
$$

The following form factor for long rigid fibrillar objects of length $2 H$, homogeneous contrast and circular cross-section was used to fit the data for Est1-4 at $70{ }^{\circ} \mathrm{C}$.

$$
I=c \overline{\Delta b}^{2} 2 H \frac{n_{L} M_{0}}{N_{a}} \int_{0}^{\pi / 2}\left[\frac{\sin (q H \cos \alpha)}{q H \cos \alpha} 2 \frac{J_{1}(q r \sin \alpha)}{q r \sin \alpha}\right]^{2} \sin \alpha d \alpha
$$

Differential scanning calorimetry. Solution-phase differential scanning calorimetry measurements were performed on a high sensitivity TA Instruments nDSC III system (baseline noise $\pm 15 \mathrm{nW})$. The sample cell $(0.3 \mathrm{~mL})$ was filled with the bis-urea solution and the reference 
cell with the corresponding solvent. The capillary cells were not capped, and a constant pressure of $510^{5} \mathrm{~Pa}$ was applied. The solutions $(5 \mathrm{mM})$, were analyzed between 20 and $70{ }^{\circ} \mathrm{C}$, using 3 full heating/cooling cycles, at $1{ }^{\circ} \mathrm{C} \min ^{-1}$. The transition temperature, $\mathrm{T} * *$, was measured from the heating scans.

Fourier Transform Infrared Spectroscopy. Solution spectra were measured on a Nicolet iS10 spectrometer in $\mathrm{KBr}$ cells of $1.0 \mathrm{~mm}$ pathlength and are corrected for air, solvent and cell absorption.

Isothermal titrating calorimetry. Isothermal titrating calorimetry data were recorded on a Microcal VP-ITC apparatus, injecting a $0.25 \mathrm{mM}$ (for Alk1) or a $1 \mathrm{mM}$ (for Est1-Est4) toluene solution of the sample into neat toluene. Injections of $5 \mu \mathrm{L}$ over 10 seconds were performed every 300 seconds at a stirring rate of $260 \mathrm{rpm}$.

\section{Results and Discussion}

Synthesis of the monomers and gelation ability. Ester bisureas (Est1-4, Scheme 1) have been synthesized in two steps starting from their respective racemic amino acids (see Supporting Information). The association properties of ester bisureas were compared with those of previously investigated alkyl bisureas Alk1, ${ }^{49,50,58} \mathbf{A l k 2} 2^{48-53,57-60}$ and Alk3. ${ }^{61}$ Notably Est1 only differs from Alk1 by the presence of an ester functionality at the $\beta$-position of the urea moieties thus allowing a direct probing of the influence of the ester function on the morphology of the self-assemblies.

\section{Scheme 1 Structure of alkyl and ester bisureas.}




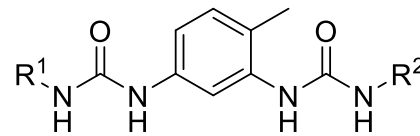

Alkyl bis-ureas
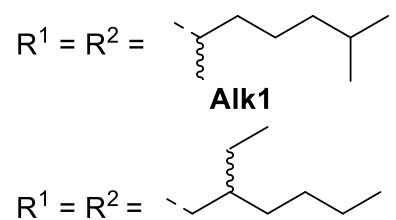

Alk2

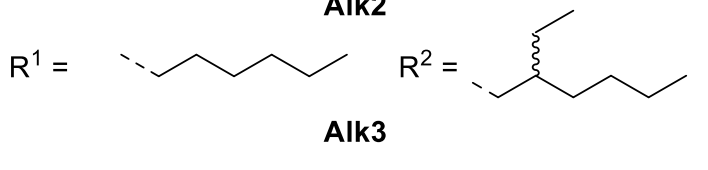

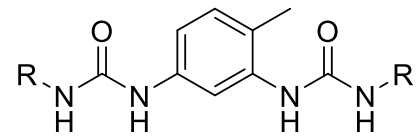

Ester bis-ureas
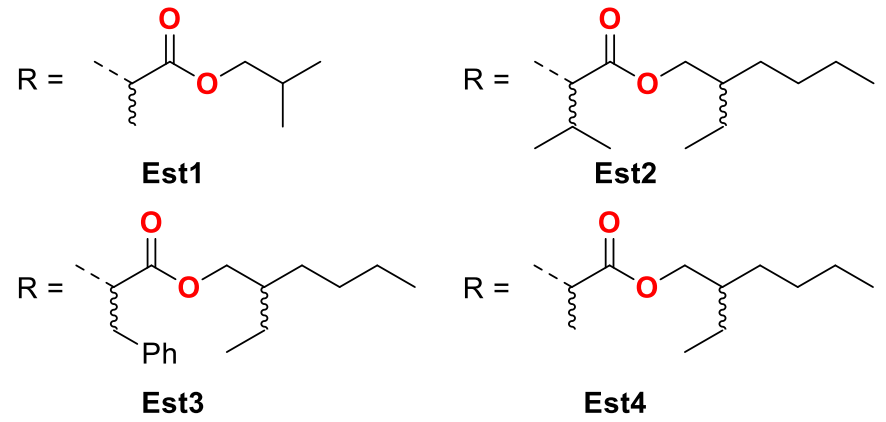

Upon dissolution of Est1-Est4 in toluene (10 mM), gels are formed (Figure S1). This is a first indication that the presence of the ester functionality does not prevent the formation of long assemblies.

Morphology of the supramolecular polymers. Small angle neutron scattering (SANS) analyses were performed in toluene- $\mathrm{d}^{8}$ for alkyl and ester bisureas at $20{ }^{\circ} \mathrm{C}$ and $70{ }^{\circ} \mathrm{C}$ (at a concentration of ca. $0.6 \mathrm{wt} \%$ ). All bisureas exhibit similar scattering profiles (Figure S2) showing a $\mathrm{q}^{-1}$ dependence typical of rod-like objects, at intermediate q values. At $20{ }^{\circ} \mathrm{C}$, the dependence is maintained down to the lowest measured scattering vector $\left(q=0.004 \AA^{-1}\right)$ indicating that the length of the rods is larger than $250 \AA$. Fitting the data according to the form factor for rigid rods with a circular cross-section and a uniform scattering length density yields the geometrical radius $(r)$ of the rods, the length $(2 H)$ of the rods and the linear density $\left(n_{\mathrm{L}}\right)$ of the repeating units along the central axis of the rods (see Experimental Section). Assuming a repeat distance of $4.6 \AA$ (as observed in the X-ray structure of 1,3-dimethylurea) between the bisurea monomers within the rods, the number of bisurea monomers (n) in the cross-section of the rods can be determined $(n=$ 4.6 $\left.n_{\mathrm{L}}\right)$. Results of the fits are listed in Table 1 . 
Table 1. Geometrical radius $(r)$, length $(2 H)$, linear density $\left(n_{\mathrm{L}}\right)$ and number of bisurea molecules (n) in the cross-section of the cylindrical objects deduced from the fit of the SANS data (see Figure S2) below and above the transition temperature $\left.\left(\mathrm{T}^{* *}\right)\right)^{\mathrm{a}, \mathrm{b}}$

\begin{tabular}{|c|c|c|c|c|c|c|c|} 
& \multicolumn{3}{|c|}{$20^{\circ} \mathrm{C}\left(<\mathrm{T}^{* *}\right)$} & \multicolumn{3}{c|}{$70^{\circ} \mathrm{C}\left(>\mathrm{T}^{* *}\right)$} & $\begin{array}{c}\mathrm{T}^{* *} \\
\left({ }^{\circ} \mathrm{C}\right)^{\mathrm{c}}\end{array}$ \\
\hline bisurea & $r(\AA)$ & $n_{\mathrm{L}}\left(\AA^{-1}\right)$ & $n^{\mathrm{d}}$ & $r(\AA)$ & $n_{\mathrm{L}}\left(\AA^{-1}\right)$ & $n^{\mathrm{d}}$ & \\
Alk1 & 14.4 & 0.56 & 2.6 & 9.0 & 0.23 & 1.1 & 61.1 \\
Alk3 & 14.1 & 0.55 & 2.5 & 8.6 & 0.22 & 1.0 & 43.0 \\
Est1 & 14.4 & 0.53 & 2.4 & 8.3 & 0.22 & 1.0 & 49.1 \\
Est2 & $13.9 \pm 0.2$ & $0.41 \pm 0.02$ & $1.9 \pm 0.1$ & 8.1 & 0.17 & 0.78 & 60.3 \\
Est3 & $16.1 \pm 0.1$ & $0.48 \pm 0.02$ & $2.2 \pm 0.1$ & 9.1 & 0.18 & 0.83 & 35.5 \\
Est4 & $15.4 \pm 0.1$ & $0.46 \pm 0.05$ & $2.1 \pm 0.2$ & 9.5 & 0.17 & 0.78 & 34.3
\end{tabular}

${ }^{a}$ SANS experiments were performed at $c a .0 .6 \mathrm{wt} \%$ except for Alk2 $(0.8 \mathrm{wt} \%)$. For each ester bisurea, SANS measurements at $20{ }^{\circ} \mathrm{C}$ were made on two different samples and the indicated values correspond to an average of the fitted data.

${ }^{\mathrm{b}}$ For Alk1-Alk3, $2 H>250 \AA$. For Est1-Est4, $2 H>250 \AA$ at $20^{\circ} \mathrm{C}$ and $2 H=160,120,120$, and $130 \AA$ at $70{ }^{\circ} \mathrm{C}$ for Est1, Est2, Est3 and Est4 respectively.

${ }^{\mathrm{c}} \mathrm{T}^{* *}$ : transition temperature between structures as determined by nano-DSC experiments (vide infra) performed at $5 \mathrm{mM}$ in toluene.

${ }^{\mathrm{d}} \mathrm{n}$ : the number of bisurea molecules in the cross-section, assuming a repeat distance of $4.6 \AA$.

For alkyl bisureas at $20{ }^{\circ} \mathrm{C}$, the values of the fits are consistent with those obtained previously ${ }^{50,52,61}$ with a linear density of $c a .0 .55 \AA^{-1}$ corresponding to a number of bisurea molecules in the cross-section of $c a$. 2.5 . For ester bisureas the linear density is smaller $\left(0.41<n_{\mathrm{L}}\right.$ $<0.48 \AA^{-1}$ ) yielding a number of molecules in the cross-section comprised between 1.9 and 2.2. The geometrical radius of the cylindrical objects formed by Alk1 and Est1 are close (ca. $14 \AA$ ) 
and consistent with the half-length of their extended conformation $(\mathrm{ca} .12 .9 \AA) .{ }^{62}$ At $70{ }^{\circ} \mathrm{C}$, the assemblies formed by alkyl and ester bisureas both rearranged into supramolecular polymers with $c a$. a single bisurea in the cross-section i.e. filaments $\left(1.0<n<1.1\right.$ and $0.78<n<0.83^{63}$ for alkyl and ester bisureas respectively). In the case of ester bisureas at $70{ }^{\circ} \mathrm{C}$, the leveling of the scattered intensity at low $\mathrm{q}$ is a clear indication of the limited size of the filaments. Their average length, deduced from the fit of a model of monodisperse filaments, is ca. $150 \AA$, i.e. about 30 bisurea units. $^{64}$

Although SANS experiments suggest that the low temperature assemblies formed by alkyl and ester bisureas do not contain the same number of molecules in the cross-section (i.e. approximately 3 and 2 respectively), no definite structural information can be obtained solely from these data. Unfotunately, the low scattered intensity at high q values prevents comparing data with a core-shell model that would probe the tubular nature of the assemblies. Previously, the presence of a cavity in the tubular structure formed by alkyl bisureas has been assessed by various experimental techniques corroborated by molecular dynamic simulations. ${ }^{51,52,60}$ In particular, it has been demonstrated that the stability of alkyl bisurea nanotubes is correlated to the lateral dimensions of the solvents that can (or cannot) fit inside their cavity. Notably, the nanotubes formed by Alk2 are destabilized in wide aromatic solvents since these solvents are hardly accommodated within the cavity of the tubes. Therefore, the transition temperature (related to the stability of the tubular assemblies) that can be measured by high sensitivity Differential Scanning Calorimetry (nano-DSC) provides an easy way to probe the existence of a cavity in bisurea-based supramolecular polymers.

Accordingly, nano-DSC analyses were performed in five aromatic solvents (toluene, $p$-xylene, 1,2,4-trimethylbenzene, 1,3,5-trimethylbenzene and 1,3,5-triethylbenzene) for alkyl and ester 
bisureas (Table 2). All DSC traces show a totally reversible endothermal peak related to the structural transition between the assemblies (Figure S3). As previously found for Alk2, the transition temperature $\left(\mathrm{T}^{* *}\right)$ of Alk1 and Alk3 strongly decreases when the width ${ }^{65}$ of the solvent increases (Figure 2 left) as a result of the destabilization of the tubular structure. Conversely, the stability of the rods formed by ester bisureas is not affected by the width of the solvent (Figure 2 right). The difference in the structures formed by the two bisurea families is obvious while comparing the $\mathrm{T}^{* *}$ values of Alk1 and Est1: the T** values of Alk1 are strongly affected by the nature of the solvent (from $65.7{ }^{\circ} \mathrm{C}$ in $p$-xylene to $24.9{ }^{\circ} \mathrm{C}$ in $1,3,5$-TEB the "wider" solvent investigated), but the $\mathrm{T}^{* *}$ values of Est1 are confined within a range of $10{ }^{\circ} \mathrm{C}$. This result argues in favor of a non-tubular morphology for the rod-like assemblies formed by ester bisureas.

Table 2 Transition temperature $\left(\mathrm{T}^{* *},{ }^{\circ} \mathrm{C}\right)$ between assemblies as determined by nano-DSC $(5 \mathrm{mM})$ in aromatic solvents of various widths $(\mathrm{W}){ }^{\mathrm{a}}$

\begin{tabular}{ccccccccc}
\hline solvent & $\mathrm{W}(\AA)^{65}$ & Alk1 & Alk2 & Alk3 & Est1 & Est2 & Est3 & Est4 \\
\hline toluene & 6.7 & 61.1 & $43.0^{\mathrm{c}}$ & 49.1 & 60.3 & 35.5 & 34.3 & 33.0 \\
$p$-xylene & 6.7 & 65.7 & $49.5^{\mathrm{c}}$ & 56.0 & 67.4 & 46.3 & 67.0 & 40.9 \\
$1,2,4-\mathrm{TMB}^{\mathrm{b}}$ & 7.5 & 54.1 & $34.1^{\mathrm{c}}$ & 42.0 & 59.7 & 36.7 & 44.4 & 34.4 \\
$1,3,5-\mathrm{TMB}^{\mathrm{b}}$ & 8.3 & 34.6 & $13.4^{\mathrm{c}}$ & 21.9 & 56.4 & 24.3 & 44.0 & 37.3 \\
$1,3,5-\mathrm{TEB}^{\mathrm{b}}$ & 10.1 & 24.9 & $<10^{\mathrm{d}}$ & 11.9 & 66.5 & 46.0 & 73.7 & 40.5
\end{tabular}

${ }^{a}$ For DSC traces see Figure S3. Indicated $\mathrm{T}^{* *}$ values measured at the maximum of the endothermal peak of the heating runs.

b $1,2,4-\mathrm{TMB}=1,2,4$-trimethylbenzene, $1,3,5-\mathrm{TMB}=1,3,5$-trimethylbenzene, $1,3,5$-TEB $=$ 1,3,5-triethylbenzene.

${ }^{\mathrm{c}} \mathrm{T}^{* *}$ determined by FTIR. ${ }^{60}$ 
${ }^{\mathrm{d}}$ No transition detected by nano-DSC $\left(\mathrm{T}^{* *}<10{ }^{\circ} \mathrm{C}\right)$.
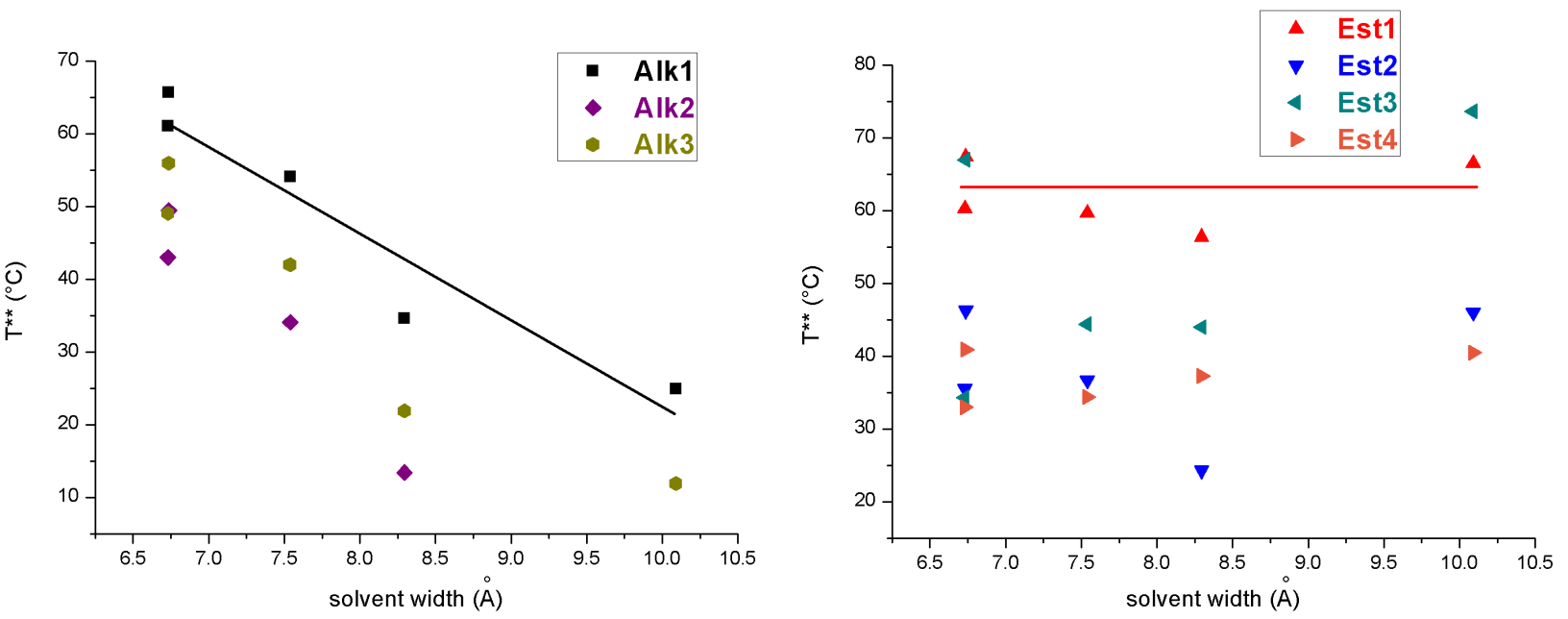

Figure 2 Transition temperature versus solvent width ${ }^{65}$ for alkyl (left) and ester (right) bisureas. The lines are drawn to visualize the evolution for Alk1 and Es1.

Molecular arrangement (local structure). While the SANS and the nano-DSC experiments indicate that the tubular structure formed by alkyl bisureas and the rod structure formed by ester bisureas exhibit distinct morphologies, these analyses provide no insight into the nature of the interactions between the bisurea monomers within the assemblies. We thus performed Fourier Transform Infrared (FTIR) analyses of ester bisureas in toluene below and above the $\mathrm{T}^{* *}$ (determined by nano-DSC, Table 2). Whatever the bisurea and the temperature, IR spectra exhibit two stretching frequencies for the N-H bonds with maxima at $v=3334 \pm 10 \mathrm{~cm}^{-1}$ and $v=$ $3275 \pm 10 \mathrm{~cm}^{-1}$ corresponding to urea-bonded aliphatic and aromatic N-H, respectively (Figures 3 and S5). ${ }^{49}$ The hydrogen-bonded assemblies are long since no peak for free N-H bonds (at $c a$. $3410 \mathrm{~cm}^{-1}$, vide infra) can be detected below or just above the structural transition. It is of importance for the characterization of the assemblies to probe a possible participation of the ester functionality in the hydrogen bond network. For Est2, the frequency associated with the ester 
carbonyl is the same in THF, in which the bisurea exists as a solvated monomer, and in toluene (Figure S4). Since a significant red shift of the ester carbonyl frequency is expected when engaged in a hydrogen bond interaction, ${ }^{66}$ this observation demonstrates that the ester functionality of Est1-Est4 is not involved in the hydrogen-bond network of the rods. This innocent role of the ester function in the hydrogen-bond network of Est1-Est4 is quite remarkable and differs from its active role in the self-assemblies of ester 1,3,5-benzene tricarboxamides in which it acts as a competitor of the amide $\mathrm{CO}$ for the bonding of the amide NH proton. ${ }^{67}$ Therefore, according to the FTIR data, the structural transition of Est1-Est4 occurs between two long urea-bonded assemblies similarly to Alk1-Alk3 (Figure S5).

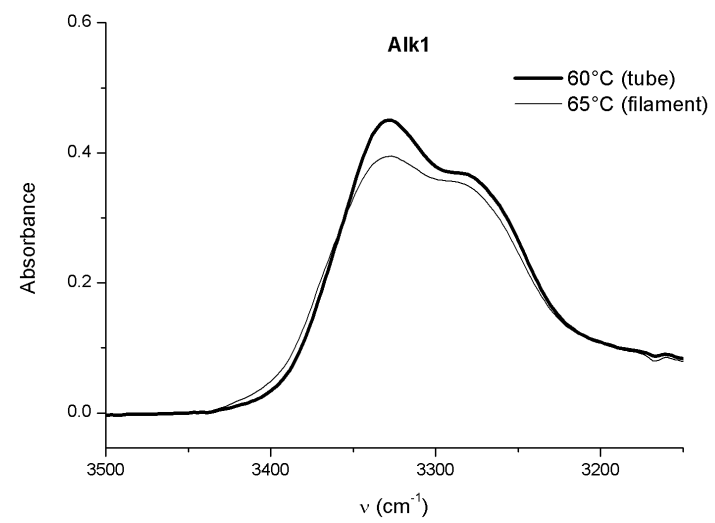

Alk1

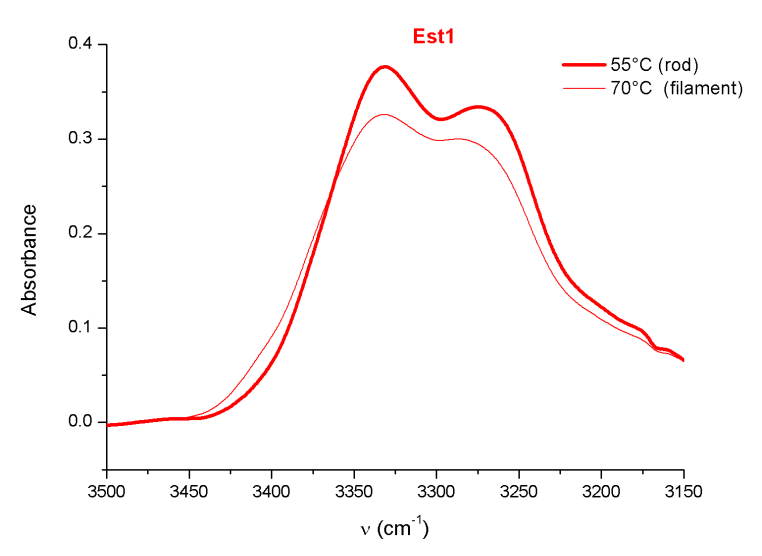

Est1

Figure 3 Infrared spectra in toluene of Alk1 (12.5 mM) and Est1 (10mM) below and above their $\mathrm{T}^{* *}$.

The shape and relative intensity of the $\mathrm{NH}$ bands are related to the conformation and environment of the urea functions within the hydrogen bond network. The aliphatic $\mathrm{N}-\mathrm{H}$ band of Alk1-Alk3 decreases in intensity and becomes wider above the $\mathrm{T}^{* *}$; it was attributed to a different pattern of the N-H bonds in the hydrogen bond network of the two structures and to a less regular assembly for the filament structure compared to the tubular structure.$^{50}$ For Est1- 
Est4, while a similar decrease in intensity and increase in width is observed for the aliphatic N-H bands, the aromatic N-H bands also undergo a significant decrease in intensity. Therefore, the difference in the shape of the N-H bands between the rod and filament structures is less obvious for the ester bisureas than it is for alkyl bisureas between the tube and filament structures (see normalized IR spectra in Figure S6). A more precise description of the $\mathrm{N}-\mathrm{H}$ pattern within the hydrogen bond network is not possible (see Figures S7-S9), but the different temperature evolution of the FTIR spectra (Figures 3 and S5) points out to a different reorganization of ester bisurea monomers during the structural transition of Est1-Est4 compared to Alk1-Alk3.

Tentative molecular arrangement for the rod structure. At low temperatures $\left(\mathrm{T}<\mathrm{T}^{* *}\right)$, the various data are coherent and show that the rod structure formed by ester bisureas is different from the tube structure displayed by alkyl bisurea. The SANS and DSC analyses (vide supra) support a non-tubular structure with two ester bisureas in the cross-section. Even though a precise picture of the molecular arrangement of the bisurea monomers within this structure is lacking at this time, a schematic structure is tentatively proposed in Figure 4: hydrogen bonds could be formed along the rod axis, and two bisureas at stage $i$ could be perpendicular to the two bisureas at the stage $i+1$. The close packing of the bisurea monomer in this structure would prevent the encapsulation of solvent molecules, corroborating the fact that the stability of the structure is not significantly affected by the size of the solvent.

At high temperatures $\left(\mathrm{T}>\mathrm{T}^{* *}\right)$, both ester and alkyl bisurea monomers self-assemble into filaments with a single molecule in the cross-section but the exact conformation of the bisurea molecules within the filament structure is unknown at this stage. Previously, MM/MD calculations performed on a small series of alkyl bisureas showed that different filament structures may exist in solution which are very close in energy. ${ }^{53}$ 


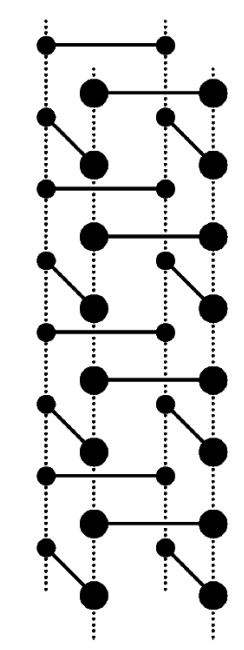

Figure 4 Proposed molecular arrangement of the ester bisureas within their rod structure. Hydrogen bonds are symbolized by dotted lines connecting the urea functions.

Structural transition In order to gain insight into the relative stabilities of the hydrogen bonded species in solution, the structural transition between the rod and filament structures of ester bisureas has been probed by means of nano-DSC, FTIR spectroscopy and isothermal titration calorimetry (ITC).

A closer look at the nano-DSC traces (Figure S3) shows that the transition between the rod and filament structures of ester bisureas is moderately cooperative and occurs over a temperature range of $c a .15^{\circ} \mathrm{C}$. It has to be compared with the highly cooperative transition between the tube and filament structures of alkyl bisureas which is complete within a temperature range of only 5 ${ }^{\circ} \mathrm{C}$. Despite this marked difference in the cooperativity of the transition, the transition temperatures $\left(\mathrm{T}^{* *}\right)$ and enthalpies $\left(\Delta \mathrm{H}^{* *}\right)$ of Alk1 and Est1 are quite similar in toluene: $\mathrm{T}^{* *}=$ $61.1^{\circ} \mathrm{C}$ and $60.3{ }^{\circ} \mathrm{C}$ respectively and $\Delta \mathrm{H}^{* *} \approx 1.0 \mathrm{kcal} \mathrm{mol}^{-1}$. Their $\mathrm{T}^{* *}$ are also quite similar in $p$-xylene and 1,2,4-TMB but the rod structure of Est1 is more stable in 1,3,5-TMB et 1,3,5-TEB since tubular structure of Alk1 is destabilized in these solvents (Table 2). Interestingly, the 
relative stability of the structures formed by ester bisureas can be tuned by modifying the nature of the alkyl group of the ester function (isobutyrate or 2-ethylhexanoate) and the nature of the substituent in the $\alpha$-position of the urea functions ( $i-\mathrm{Pr}, \mathrm{Me}$ or Bn). Although Est1 and Est4 have similar structures in solution (see SANS and IR analyses above), Est4 exhibits significantly lower transition temperatures in all the investigated aromatic solvents $\left(32.6<\mathrm{T}^{* *}<40.6^{\circ} \mathrm{C}\right.$ for Est4 vs $56.4<\mathrm{T}^{* *}<67.4{ }^{\circ} \mathrm{C}$ for Est1). It implies that the 2-ethylhexyl side chain strongly destabilizes the rod structure. Previously, such drastic effect on the value of the transition temperature exerted by small changes in the nature of the bisurea side chains was ascribed to the interactions between alkyl groups or solvation effects. ${ }^{61}$

The structural transition of ester bisureas was followed by measuring FTIR spectra every $5{ }^{\circ} \mathrm{C}$ between 25 and $100{ }^{\circ} \mathrm{C}$ in toluene $(10 \mathrm{mM})$. The maximum absorbance of the aliphatic $\mathrm{NH}$ band is normalized by the absorbance at $3300 \mathrm{~cm}^{-1}$ and plotted versus the temperature (Figure S10). ${ }^{50}$ For all ester bisureas, a steep decrease in the absorbance ratio is observed at a temperature consistent with $\mathrm{T}^{* *}$ determined by nano-DSC. The decrease of the absorbance ratio occurs over a wide temperature range confirming that the transition is moderately cooperative. Above the transition, a shoulder appears at $c a .3410 \mathrm{~cm}^{-1}$ which corresponds to free $\mathrm{N}-\mathrm{H}$ and its intensity increases upon further rising the temperature. These free urea functions can be attributed to the bisurea molecules located at the extremities of the filaments and/or to free monomers. These observations corroborate the SANS experiments performed at $70{ }^{\circ} \mathrm{C}$ since the fitted data indicate that the filaments formed by ester bisurea are short (see Table 1 and Figure S2).

Isothermal titration calorimetry (ITC) is a particularly suitable technique to probe the dynamic nature and stability of supramolecular polymers. ${ }^{48,59}$ ITC analyses were performed by injecting a solution of Est1-Est4 at $1 \mathrm{mM}$ in toluene into a calorimetric cell containing pure toluene at 20 
${ }^{\circ} \mathrm{C}$. In all cases, we observed similar heat flow curves composed of endothermal peaks of decreasing intensities upon incremental addition of bisurea. These endothermic peaks are related to the disruption of the hydrogen-bonded assemblies upon dilution. Above a certain critical concentration, the self-assemblies in the cell are stable enough and no more dissociation into monomers occurs. Enthalpograms of Est1-Est4 were obtained by integration of the heat flow peaks (Figure S11 a and b). Alk1 and Est1 present qualitatively similar enthalpograms: a sharp decrease of the heat of dissociation occurs and no more dissociation is observed afterwards. ${ }^{58}$ For Alk1, the transition was shown to be due to the disassembly of the tubular supramolecular polymers directly into monomers. Given that the transition enthalpy for Alk1 and Est1 are very similar $\left(\Delta \mathrm{H}^{*} \approx 11 \mathrm{kcal} . \mathrm{mol}^{-1}\right)$ and that no further dissociation is observed after the transition, it is likely that the transition observed by ITC for Est1 corresponds to the transition from the rod supramolecular polymers to the monomers. The critical concentration $\mathrm{c}^{*}$, which corresponds to the concentration at which the rod structure is predominantly present over the monomers, can be extracted from the ITC data: $2.6 \times 10^{-5} \mathrm{M}$ and $1.5 \times 10^{-4} \mathrm{M}$ for Alk1 and Est1 respectively (25 $\left.{ }^{\circ} \mathrm{C}\right)$. The $\mathrm{c}^{*}$ of Est1 is higher than the one of Alk1 suggesting that the ester functionality decreases the self-assembling capabilities of ester bisurea monomers. However, the competing ester groups do not prevent the association into long supramolecular polymers.

The comparison of transition enthalpies (Figure S11 b) indicates that for Est2, the dissociation also occurs from rods into monomers $\left(\Delta \mathrm{H}^{*} \approx 11 \mathrm{kcal} \cdot \mathrm{mol}^{-1}\right)$, but the transition lies at higher $\mathrm{c}^{*}$ $\left(1.3 \times 10^{-4} \mathrm{M}\right)$ than that of Est1 $\left(8.4 \times 10^{-5} \mathrm{M}\right.$, at $\left.20^{\circ} \mathrm{C}\right)$, consistent with the lower stability of its rod structure observed by nano-DSC. For Est3, the first injections observed by ITC also correspond to the dissociation from rods into monomers $\left(\Delta \mathrm{H}^{*} \approx 11 \mathrm{kcal} \cdot \mathrm{mol}^{-1}\right)$, but at the end of the titration, the significant heat effects that remain $\left(\Delta \mathrm{H}=1.8 \mathrm{kcal} \cdot \mathrm{mol}^{-1}\right)$ indicate that the 
monomers rearrange into filaments, because of the sufficiently high concentration in the cell. The transition observed $\left(\mathrm{c}^{*}=1.3 \times 10^{-4} \mathrm{M}\right)$ is thus the transition from monomers to the filaments. In the case of Est4, the two regimes are clearly visible: after dissociation of the rod structure into monomer, the monomers in the cell assemble into filaments $\left(\Delta \mathrm{H}^{*} \approx 9.0 \mathrm{kcal}^{\mathrm{mol}}{ }^{-1}\right)$ and then the filaments in the cell rearrange into tubes $\left(\Delta \mathrm{H}^{* *}=1.8 \mathrm{kcal}^{*} \mathrm{~mol}^{-1}\right)$. The latter value is in agreement with the transition enthalpy measured by DSC. Thus the two transitions, between monomers and filaments $\left(\mathrm{c}^{*}=1.2 \times 10^{-4} \mathrm{M}\right)$ and between filaments and rods $\left(\mathrm{c}^{* *}=2.8 \times 10^{-4}\right.$ $\mathrm{M})$, can be distinguished. It is interesting to note that despite similar $\mathrm{T}^{* *}$ at $\mathrm{mM}$ concentrations, Est2-Est4 exhibit different critical concentrations at $20^{\circ} \mathrm{C}$.

Pseudo-phase diagrams The transition temperatures and critical concentrations measured by ITC, DSC and FTIR enable the construction of pseudo-phase diagrams highlighting the stability of the hydrogen-bonded polymers in toluene relative to their monomers. Notably comparing the pseudo-phase diagram of Alk1 and Est1 is particularly instructive concerning the impact of the ester functionality on the self-assembly of the bisurea monomers (Figure 5). At low concentrations, the tubular structure formed by Alk1 is more stable than the rod structure of Est1 


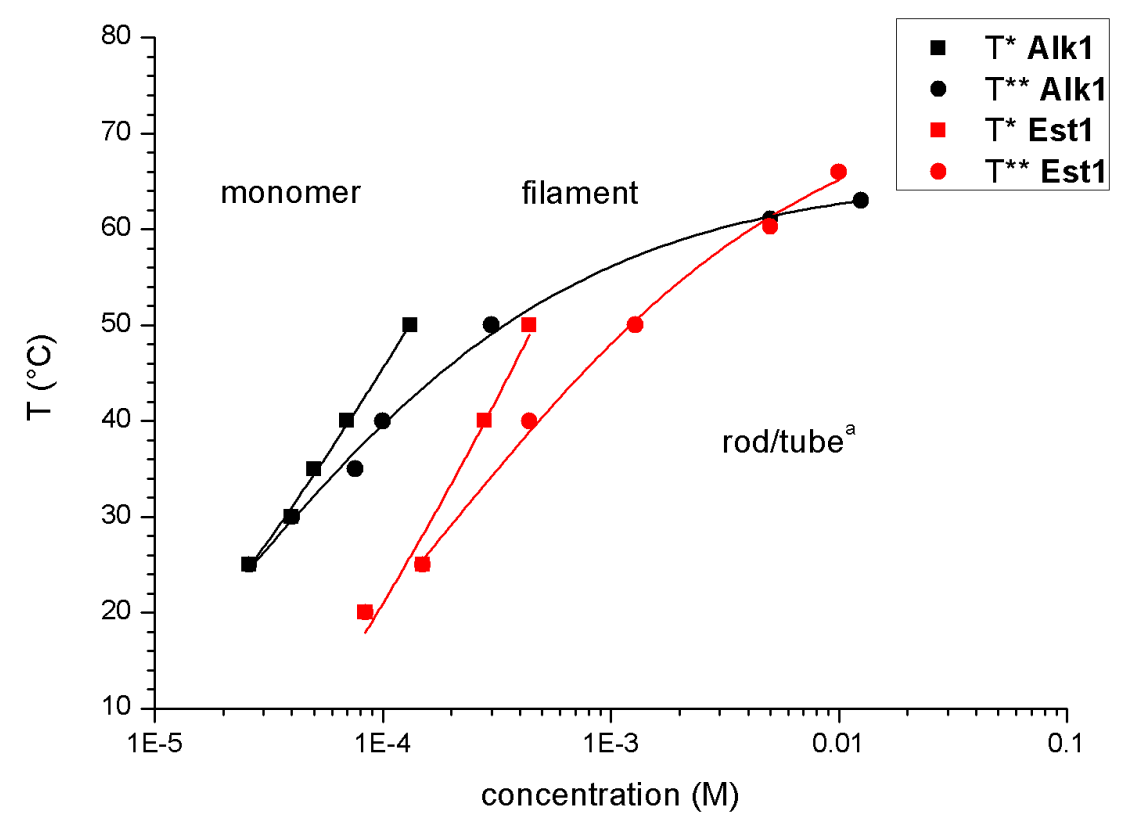

Figure 5 Comparison of the pseudo-phase diagrams of Alk1 and Est1 in toluene. ${ }^{a}$ The low temperature structures displayed by Alk1 and Est1 have different morphologies (vide supra). The lines are drawn to guide the eye.

by less than one magnitude order. At a concentration of a few $\mathrm{mM}$, the low temperature structures of Alk1 and Est1, although having different morphologies, show similar stabilities.

Finally, it is of interest to compare the pseudo-phase diagrams of Est1-Est4 (Figure S12). The nature of the amino-ester and alkyl moieties apparently affect much more the equilibrium between rods and filaments than between filaments and monomer. Notably, the stability of the rod relative to the filament decreases in the order Est1 $>>$ Est2 $>$ Est4 $>>$ Est3 possibly in line with the increased steric bulk. In contrast, this structural feature has no significant influence on the filament to monomer transition, which can be understood by the probably less densely packed filament structure. Whatever the reason, the nature of amino-ester and alkyl moieties can be used 
to select one structure over the other in a given solvent which is of great interest for many applications. $^{41-47}$

Conclusion At first sight, alkyl and ester bisureas have similar association properties: i) selfassemblies formed at $\mathrm{mM}$ concentration and room temperature are sufficiently long and rigid to gelate toluene, ii) these supramolecular polymers are in competition in solution with a supramolecular polymer which contains a single bisurea molecule in its cross-section (filaments), iii) both supramolecular polymers are composed of urea-bonded bisurea monomers. Nevertheless, the molecular arrangements of the bisurea monomers in the room temperature assemblies are different: alkyl bisureas form a supramolecular polymer with a tubular morphology while the rod-like structure of ester bisureas has no cavity.

The impact of the ester functionality on the self-association properties of bisurea monomers and on the molecular arrangement of the monomer within the rod-like structure is subtle because despite its hydrogen-bonded acceptor nature, the ester moiety does not participate in the hydrogen bond network. Quantitative data on the stability of the hydrogen-bonded species in solution indicate that the ester function reduces only moderately the self-association capability of the bisurea monomers: rod-like assemblies are stable at $\mathrm{mM}$ concentration and room temperature. Precise probing of the role of the ester moiety also reveals that the ester functionality influences the cooperativity between the polymeric structures as well as their relative stabilities. Importantly, the nature of the substituent in the $\alpha$-position of the urea functions and the nature of the alkyl group of the ester moiety can be used to tune the relative stabilities of the rod and filament self-assemblies. Ongoing work in our laboratory includes the elucidation of the rod structure formed by ester bisureas and the use of ester bisurea as co- 
monomers for different applications including probing weak interactions and asymmetric catalysis.

\section{Associated Content}

Supporting Information.

Table S1, Table S2, Figures S1 to S12 and the synthesis and characterization of bisurea monomers and their precursors. This material is available free of charge via the Internet at http://pubs.acs.org/.

\section{Author Information}

\section{Acknowledgements}

Support from the French Agence Nationale de la Recherche is acknowledged (project ANR12-BS08-0019 BalanceSupra). We thank François Boué (LLB, Saclay) for assistance with SANS experiments.

Table of content

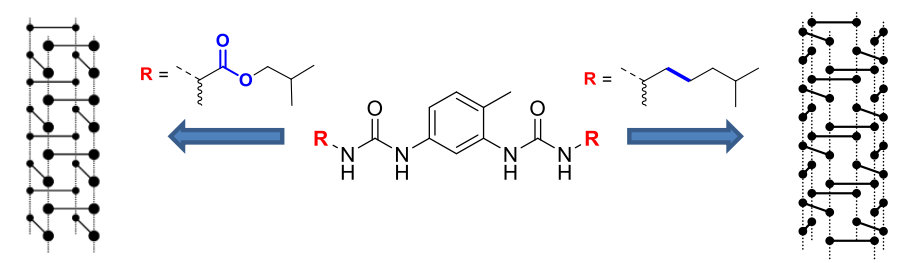




\section{References}

1. Brunsveld, L.; Folmer, B. J. B.; Meijer, E. W.; Sijbesma, R. P. Supramolecular polymers Chem. Rev. 2001, 101, 4071-4097.

2. Supramolecular Polymers, Second Edition 2005 edited by Ciferri, A. CRC Press - Taylor and Francis

3. De Greef, T. F. A.; Smulders, M. M. J.; Wolffs, M.; Schenning, A. P. H. J.; Sijbesma, R. P.; Meijer, E. W. Supramolecular Polymerization Chem. Rev. 2009, 109, 5687-5754.

4. Yang, L.; Tan, X.; Wang, Z.; Zhang, X. Supramolecular Polymers: Historical Development, Preparation, Characterization, and Functions Chem. Rev. 2015, 115, 7196-7239.

5. Yan, X. Z.; Wang, F.; Zheng, B.; Huang, F. H. Stimuli-responsive supramolecular polymeric materials Chem. Soc. Rev. 2012, 41, 6042-6065.

6. Hoeben, F. J. M.; Jonkheijm, P.; Meijer, E. W.; Schenning, A. P. H. J. About supramolecular assemblies of $\pi$-conjugated systems Chem. Rev. 2005, 105, 1491-1546.

7. Babu, S. S.; Praveen, V. K.; Ajayaghosh, A. Functional $\pi$-Gelators and Their Applications Chem. Rev. 2014, 114, 1973-2129.

8. Das, A.; Ghosh, S. Supramolecular Assemblies by Charge-Transfer Interactions between Donor and Acceptor Chromophores Angew. Chem. Int. Ed. 2014, 53, 2038-2054.

9. Hart, L. R.; Harries, J. L.; Greenland, B. W.; Colquhoun, H. M.; Hayes, W. Healable supramolecular polymers Polymer Chem. 2013, 4, 4860-4870. 
10. Herbst, F.; Dohler, D.; Michael, P.; Binder, W. H. Self-Healing Polymers via Supramolecular Forces Macromol. Rapid. Commun. 2013, 34, 203-220.

11. Roy, N.; Bruchmann, B.; Lehn, J. M. DYNAMERS: dynamic polymers as self-healing materials Chem. Soc. Rev. 2015, 44, 3786-3807.

12. de Jong, J. J. D.; Lucas, L. N.; Kellogg, R. M.; van Esch, J. H.; Feringa, B. L. Reversible optical transcription of supramolecular chirality into molecular chirality Science 2004, 304, 278281.

13. Dijken, D. J.; Beierle, J. M.; Stuart, M. C. A.; Szymanski, W.; Browne, W. R.; Feringa, B. L. Autoamplification of Molecular Chirality through the Induction of Supramolecular Chirality Angew. Chem. Int. Ed. 2014, 53, 5073-5077.

14. Hirst, A. R.; Escuder, B.; Miravet, J. F.; Smith, D. K. High-Tech Applications of SelfAssembling Supramolecular Nanostructured Gel-Phase Materials: From Regenerative Medicine to Electronic Devices Angew. Chem. Int. Ed. 2008, 47, 8002-8018.

15. Dawn, A.; Shiraki, T.; Haraguchi, S.; Tamaru, S.; Shinkai, S. What Kind of "Soft Materials" Can We Design from Molecular Gels? Chem. Asian J. 2011, 6, 266-282.

16. Zhao, D. H.; Moore, J. S. Nucleation-elongation: a mechanism for cooperative supramolecular polymerization Org. Biomol. Chem. 2003, 1, 3471-3491.

17. Kulkarni, C.; Balasubramanian, S.; George, S. J. What Molecular Features Govern the Mechanism of Supramolecular Polymerization? ChemPhysChem 2013, 14, 661-673. 
18. Rest, C.; Kandanelli, R.; Fernandez, G. Strategies to create hierarchical self-assembled structures via cooperative non-covalent interactions Chem. Soc. Rev. 2015, 44, 2543-2572.

19. Lohr, A.; Wurthner, F. Chiral Amplification, Kinetic Pathways, and Morphogenesis of Helical Nanorods upon Self-assembly of Dipolar Merocyanine Dyes Isr. J. Chem. 2011, 51, 1052-1066.

20. Tidhar, Y.; Weissman, H.; Wolf, S. G.; Gulino, A.; Rybtchinski, B. Pathway-Dependent Self-Assembly of Perylene Diimide/Peptide Conjugates in Aqueous Medium Chem. Eur. J. 2011, 17, 6068-6075.

21. Korevaar, P. A.; George, S. J.; Markvoort, A. J.; Smulders, M. M. J.; Hilbers, P. A. J.; Schenning, A. P. H. J.; De Greef, T. F. A.; Meijer, E. W. Pathway complexity in supramolecular polymerization Nature 2012, 481, 492-497.

22. Tidhar, Y.; Weissman, H.; Tworowski, D.; Rybtchinski, B. Mechanism of Crystalline Self-Assembly in Aqueous Medium: A Combined Cryo-TEM/Kinetic Study Chem. Eur. J. 2014, $20,10332-10342$.

23. Ogi, S.; Fukui, T.; Jue, M. L.; Takeuchi, M.; Sugiyasu, K. Kinetic Control over Pathway Complexity in Supramolecular Polymerization through Modulating the Energy Landscape by Rational Molecular Design Angew. Chem. Int. Ed. 2014, 53, 14363-14367.

24. Wang, X. S.; Guerin, G.; Wang, H.; Wang, Y. S.; Manners, I.; Winnik, M. A. Cylindrical block copolymer micelles and co-micelles of controlled length and architecture Science 2007, $317,644-647$. 
25. Gilroy, J. B.; Gadt, T.; Whittell, G. R.; Chabanne, L.; Mitchels, J. M.; Richardson, R. M.; Winnik, M. A.; Manners, I. Monodisperse cylindrical micelles by crystallization-driven living self-assembly Nature Chem. 2010, 2, 566-570.

26. Zhang, W.; Jin, W. S.; Fukushima, T.; Saeki, A.; Seki, S.; Aida, T. Supramolecular Linear Heterojunction Composed of Graphite-Like Semiconducting Nanotubular Segments Science 2011, 334, 340-343.

27. Ogi, S.; Sugiyasu, K.; Manna, S.; Samitsu, S.; Takeuchi, M. Living supramolecular polymerization realized through a biomimetic approach Nature Chem. 2014, 6, 188-195.

28. Kumar, J.; Tsumatori, H.; Yuasa, J.; Kawai, T.; Nakashima, T. Self-Discriminating Termination of Chiral Supramolecular Polymerization: Tuning the Length of Nanofibers Angew. Chem. Int. Ed. 2015, 54, 5943-5947.

29. Kang, J.; Miyajima, D.; Mori, T.; Inoue, Y.; Itoh, Y.; Aida, T. A rational strategy for the realization of chain-growth supramolecular polymerization Science 2015, 347, 646-651.

30. Aida, T.; Meijer, E. W.; Stupp, S. I. Functional Supramolecular Polymers Science 2012, $335,813-817$.

31. Brunsveld, L.; Zhang, H.; Glasbeek, M.; Vekemans, J. A. J. M.; Meijer, E. W. Hierarchical growth of chiral self-assembled structures in protic media J. Am. Chem. Soc. 2000, $122,6175-6182$.

32. Nyrkova, I. A.; Semenov, A. N.; Aggeli, A.; Boden, N. Fibril stability in solutions of twisted $\beta$-sheet peptides: a new kind of micellization in chiral systems Eur. Phys. J. B 2000, 17, 481-497. 
33. Aggeli, A.; Nyrkova, I. A.; Bell, M.; Harding, R.; Carrick, L.; McLeish, T. C. B.; Semenov, A. N.; Boden, N. Hierarchical self-assembly of chiral rod-like molecules as a model for peptide $\beta$-sheet tapes, ribbons, fibrils, and fibers Proc. Natl. Acad. Sci. U. S. A. 2001, 98, 11857-11862.

34. Stals, P. J. M.; Korevaar, P. A.; Gillissen, M. A. J.; de Greef, T. F. A.; Fitie, C. F. C.; Sijbesma, R. P.; Palmans, A. R. A.; Meijer, E. W. Symmetry Breaking in the Self-Assembly of Partially Fluorinated Benzene-1,3,5-tricarboxamides Angew. Chem. Int. Ed. 2012, 51, 1129711301.

35. Gillissen, M. A. J.; Koenigs, M. M. E.; Spiering, J. J. H.; Vekemans, J. A. J. M.; Palmans, A. R. A.; Voets, I. K.; Meijer, E. W. Triple Helix Formation in Amphiphilic Discotics: Demystifying Solvent Effects in Supramolecular Self-Assembly J. Am. Chem. Soc. 2014, 136, 336-343.

36. Shen, Z. C.; Wang, T. Y.; Liu, M. H. Macroscopic Chirality of Supramolecular Gels Formed from Achiral Tris(ethyl cinnamate) Benzene-1,3,5-tricarboxamides Angew. Chem. Int. Ed. 2014, 53, 13424-13428.

37. Baram, J.; Weissman, H.; Tidhar, Y.; Pinkas, I.; Rybtchinski, B. Hydrophobic SelfAssembly Affords Robust Noncovalent Polymer Isomers Angew. Chem. Int. Ed. 2014, 53, 41234126.

38. Qiu, H. B.; Hudson, Z. M.; Winnik, M. A.; Manners, I. Multidimensional hierarchical self-assembly of amphiphilic cylindrical block comicelles Science 2015, 347, 1329-1332. 
39. Domoto, Y.; Busseron, E.; Maaloum, M.; Moulin, E.; Giuseppone, N. Control over Nanostructures and Associated Mesomorphic Properties of Doped Self-Assembled Triarylamine Liquid Crystals Chem. Eur. J. 2015, 21, 1938-1948.

40. Rodler, F.; Schade, B.; Jäger, C. M.; Backes, S.; Hampel, F.; Böttcher, C.; Clark, T.; Hirsch, A. Amphiphilic Perylene-Calix[4]arene Hybrids: Synthesis and Tunable Self-Assembly J. Am. Chem. Soc. 2015, 137, 3308-3317.

41. Armao, J. J.; Maaloum, M.; Ellis, T.; Fuks, G.; Rawiso, M.; Moulin, E.; Giuseppone, N. Healable Supramolecular Polymers as Organic Metals J. Am. Chem. Soc. 2014, 136, 1138211388.

42. Guler, M. O.; Stupp, S. I. A self-assembled nanofiber catalyst for ester hydrolysis $J$. Am. Chem. Soc. 2007, 129, 12082-12083.

43. Escuder, B.; Rodriguez-Llansola, F.; Miravet, J. F. Supramolecular gels as active media for organic reactions and catalysis New. J. Chem. 2010, 34, 1044-1054.

44. Rodriguez-Llansola, F.; Meijer, E. W. Supramolecular Autoregulation J. Am. Chem. Soc. 2013, $135,6549-6553$.

45. de Torres, M.; van Hameren, R.; Nolte, R. J. M.; Rowan, A. E.; Elemans, J. A. A. W. Photocatalytic oxidation of stilbene by self-assembled stacks of manganese porphyrins Chem. Commun. 2013, 49, 10787-10789.

46. Raynal, M.; Portier, F.; van Leeuwen, P. W. N. M.; Bouteiller, L. Tunable Asymmetric Catalysis through Ligand Stacking in Chiral Rigid Rods J. Am. Chem. Soc. 2013, 135, 1768717690. 
47. Huerta, E.; van Genabeek, B.; Lamers, B. A. G.; Koenigs, M. M. E.; Meijer, E. W.; Palmans, A. R. A. Triggering Activity of Catalytic Rod-Like Supramolecular Polymers Chem. Eur. J. 2015, 21, 3682-3690.

48. Bellot, M.; Bouteiller, L. Thermodynamic Description of Bis-urea Self-Assembly: Competition between Two Supramolecular Polymers Langmuir 2008, 24, 14176-14182.

49. Simic, V.; Bouteiller, L.; Jalabert, M. Highly cooperative formation of bis-urea based supramolecular polymers J. Am. Chem. Soc. 2003, 125, 13148-13154.

50. Bouteiller, L.; Colombani, O.; Lortie, F.; Terech, P. Thickness transition of a rigid supramolecular polymer J. Am. Chem. Soc. 2005, 127, 8893-8898.

51. Shikata, T.; Nishida, T.; Isare, B.; Linares, M.; Lazzaroni, R.; Bouteiller, L. Structure and dynamics of a bisurea-based supramolecular polymer in n-dodecane J. Phys. Chem. B 2008, 112, 8459-8465.

52. Isare, B.; Linares, M.; Lazzaroni, R.; Bouteiller, L. Engineering the Cavity of SelfAssembled Dynamic Nanotubes J. Phys. Chem. B 2009, 113, 3360-3364.

53. Brocorens, P.; Linares, M.; Guyard-Duhayon, C.; Guillot, R.; Andrioletti, B.; Suhr, D.; Isare, B.; Lazzaroni, R.; Bouteiller, L. Conformational Plasticity of Hydrogen Bonded Bis-urea Supramolecular Polymers J. Phys. Chem. B 2013, 117, 5379-5386.

54. Ouhib, F.; Raynal, M.; Jouvelet, B.; Isare, B.; Bouteiller, L. Hydrogen bonded supramolecular polymers in moderately polar solvents Chem. Commun. 2011, 47, 10683-10685. 
55. Isare, B.; Pembouong, G.; Boue, F.; Bouteiller, L. Conformational Control of HydrogenBonded Aromatic Bis-Ureas Langmuir 2012, 28, 7535-7541.

56. Giannicchi, I.; Jouvelet, B.; Isare, B.; Linares, M.; Dalla Cort, A.; Bouteiller, L. Orthohalogen substituents dramatically enhance hydrogen bonding of aromatic ureas in solution Chem. Commun. 2014, 50, 611-613.

57. Lortie, F.; Boileau, S.; Bouteiller, L.; Chassenieux, C.; Deme, B.; Ducouret, G.; Jalabert, M.; Laupretre, F.; Terech, P. Structural and rheological study of a bis-urea based reversible polymer in an apolar solvent Langmuir 2002, 18, 7218-7222.

58. Isare, B.; Bouteiller, L.; Ducouret, G.; Lequeux, F. Tuning reversible supramolecular polymer properties through co-monomer addition Supramol. Chem. 2009, 21, 416-421.

59. Arnaud, A.; Bouteiller, L. Isothermal titration calorimetry of supramolecular polymers Langmuir 2004, 20, 6858-6863.

60. Pinault, T.; Isare, B.; Bouteiller, L. Solvents with similar bulk properties induce distinct supramolecular architectures ChemPhysChem 2006, 7, 816-819.

61. Roman, M.; Cannizzo, C.; Pinault, T.; Isare, B.; Andrioletti, B.; van der Schoot, P.; Bouteiller, L. Supramolecular Balance: Using Cooperativity To Amplify Weak Interactions $J$. Am. Chem. Soc. 2010, 132, 16818-16824.

62. The van der Waals surface of the extended conformation of Alk1 and Est1 was generated by substituting every atoms with spheres having van der Waals radius (Winmostar software ${ }^{\circledR}$ ). Geometry optimization was performed through molecular mechanic method (MM3) using the software Scigress (Fujitsu®). 
63. The obtained values for $\mathrm{n}$ smaller than 1 are an indication for the presence of a significant

\section{fraction of very short filaments (or monomers) which have a very low scattered intensity.}

64. Of course, the filaments are not expected to have a monodisperse length.

65. The width corresponds to the diameter of the cylinder having minimum diameter in which the solvent molecule inscribes (Winmostar ${ }^{\circledR}$ software). Geometry optimization was performed through a molecular mechanic method (MM3) using the software Scigress (Fujitsu®).

66. Scerba, M. T.; DeBlase, A. F.; Bloom, S.; Dudding, T.; Johnson, M. A.; Lectka, T. Characterization of Highly Unusual NH+-O Hydrogen Bonding to Ester Ether Oxygen Atoms through Spectroscopic and Computational Studies J. Phys. Chem. A 2012, 116, 3556-3560.

67. Desmarchelier, A.; Raynal, M.; Brocorens, P.; Vanthuyne, N.; Bouteiller, L. Revisiting the assembly of amino ester-based benzene-1,3,5-tricarboxamides: chiral rods in solution Chem. Commun. 2015, 51, 7397-7400. 